\title{
COCAINE: TRIGGER FOR FIBROMYALGIA OR WITHDRAWAL SYNDROME?
}

Diogo Rios Avila (UFMT, Sinop, MT, Brasil), Fabiana de Castro Machado (UFMT, Sinop, MT, Brasil), Gabriel Freitas de Campos (UFMT, Sinop, MT, Brasil), Andressa Gabriely Rodrigues Beserra (UFMT, Sinop, MT, Brasil), Allana Campos Alves (UFMT, Sinop, MT, Brasil), Gabriel Ribeiro Leão Barroso (UFMT, Sinop, MT, Brasil), Heloisa Maria Lopes Scarinci (UFMT, Sinop, MT, Brasil), Flavio Fernandes Barboza (UFMT, Sinop, MT, Brasil)

\section{BACKGROUND}

Cocaine acts predominantly in the central nervous system, enhancing the release and duration of action of dopamine, noradrenaline and serotonin, the latter two related to mood, cognition and eventual pain functions. Withdrawal syndrome (WS) usually starts 4 to 10 days after cocaine has been discontinued and may also occur indefinitely in a minority of cases, being characterized by psychiatric effects such as depression and, rarely, pain. Similarly, fibromyalgia (FM) is a condition that imposes differential diagnosis. Infrequent FM incidence in men is worth mentioning.

\section{CASE REPORT}

A 22-year-old man had been a cocaine user for a year and a half. Forty days after the definitive suspension of the drug, he began to present diffuse and intense pain throughout the body, in addition to sadness, insomnia and non-repairing sleep. Laboratory tests excluded other differential inflammatory diagnoses. After eight months, the patient maintained the clinical condition without improvement, using escitalopram and alprazolam, besides undergoing psychiatric follow-up. Patient diagnosis was compatible with FM by the old (16/18 tenders) and new (WPI 18 and SS 11) criteria. Duloxetine therapy with cyclobenzaprine was initiated, escitalopram was suspended, and regular physical activity was introduced. Despite 100\% improvement in the condition, the patient abandoned treatment and relapsed after 3 months. With the patient abstained for almost a year, the regimen for diffuse pain (DP) was restarted, with great sequential improvement.

\section{CONCLUSION}

The rheumatologist should not ignore the differential diagnosis conditions associated with FM-like symptoms. Its incidence in young men should stimulate further investigation of secondary causes such as substance abuse and WS. Despite the difficulty of differentiating between FM as a trigger to the suspension of cocaine use and the symptoms of WS with painful manifestation, regardless of the time of late onset, the DP and humoral treatments occur in the same way. 